\title{
O QUE É PESQUISA PSICANALÍTICA?
}

Isac Nikos Iribarry

Psicólogo,

psicanalista, escritor

e mestre em

psicologia do desenvolvimento, Laboratório de Psicanálise e Aprendizagem, Instituto de Psicologia da Universidade Federal do Rio Grande do Sul.
RESUMO: Este artigo apresenta considerações preliminares sobre uma tentativa de exposição do método da pesquisa psicanalítica. Assim sendo, tal pesquisa é examinada do ponto de vista de sua singularidade e de sua relação com o significante tomado em oposição ao signo. Seu delineamento, bem como sua dinâmica, são focalizados por esta reflexão que pretende sugerir algumas aproximações mínimas sobre os procedimentos para coleta e análise de dados numa situação psicanalítica de pesquisa. Ademais, são apresentados o ensaio metapsicológico e a construção do caso como procedimentos para discussão dos resultados, de maneira que se possa refletir sobre suas características através de uma comparação e diferenciação em relação ao estudo de caso.

Palavras-chave: Pesquisa psicanalítica, ensaio metapsicológico, construção de caso.

ABSTRACT: What is psychoanalytic research? The present article is on preliminary considerations on an attempt to present the psychoanalytical research method. Thus the psychoanalytical research is discussed on the scope of its singularity and on its relation to the significant taken in opposition to the sign. Its design, as well as its dynamic are focused on this reflection which aims at suggesting a few approaches on the procedures to data gathering and analysis in psychoanalytical research. Furthermore, the metapsychological essay and the case construction are presented as procedures to discuss the results. Thus, it makes possible the reflection on its own characteristics through a comparison to the case study also pointing out the differences between those (i.e. case study and psychoanalytical research).

Keywords: Psychoanalytical research, metapsychological essay, case construction. 


\section{INTRODUÇÃO}

Atualmente, muitos psicanalistas têm procurado a universidade como espaço de interlocução, pesquisa e reflexão. Muitos, inclusive, são docentes e trabalham diretamente com os cursos de graduação e pós-graduação. Há, no entanto, aqueles que estão iniciando seu percurso acadêmico de modo concomitante a uma trajetória clínica ou que, depois de uma longa experiência clínica, desejam se tornar pesquisadores e até professores universitários.

Para a pesquisa e a docência, o caminho é o do pós-graduação. O panorama das universidades brasileiras é amplo e muitos programas de pós-graduação em psicologia oferecem em suas áreas de concentração a possibilidade de se desenvolver um trabalho no campo psicanalítico. Quando observamos a diversidade teórica e metodológica deste panorama, logo encontramos as orientações quantitativistas e qualitativistas como predominantes e, portanto, como principais espectros em que se realizam as pesquisas de mestrado e doutorado em psicologia. Há ainda aqueles programas que, embora menos numerosos e vinculados aos cursos de psicologia de que se originaram, desenvolvem programas de pós-graduação com ênfases em especialização, mestrado e doutorado, focalizando a psicanálise como área de concentração. De qualquer modo, muito freqüentemente podemos observar que as metodologias qualitativas, como o estudo de caso, por exemplo, são as mais utilizadas nas pesquisas que se estabelecem através do foco da psicanálise. Todavia, o final do século XX foi marcado, entre outras coisas, por uma crise positiva nas pesquisas realizadas por psicanalistas que buscam a especialização, o mestrado e o doutorado.

As metodologias qualitativas, como o estudo de caso, bastante divulgado pelos trabalhos de Allones (1989), Stake (1994) e Yin (1993), por exemplo, fizeram par com as metodologias sugeridas como alternativas para o estabelecimento do caso na pesquisa psicanalítica. Podemos destacar o trabalho de Fédida (1992) e sua proposição diferenciada do estudo de caso denominada construção do caso. Assim, foi preciso procurar em Freud uma orientação metodológica, retomando a vertente daquele que lançou as bases e os fundamentos da pesquisa psicanalítica.

Foi assim que a Psychoanalytische forschung (pesquisa psicanalítica) - expressão que aparece ao longo dos textos freudianos - começou a ensaiar seus primeiros passos na universidade. É cada vez mais freqüente a procura pela pesquisa psicanalítica e muitos profissionais que optam pelo caminho da pós-graduação desejam pautar suas investigações a partir de uma apropriação do método freudiano. Podemos citar o caso de dois laboratórios de que temos conhecimento, não excluindo a forte possibilidade de outros pesquisadores associados em torno da mesma proposta em outras universidades brasileiras: o Laboratório de Psicopatologia Fundamental da PUC-SP e o Laboratório de Psicanálise e Aprendizagem da UFRGS. 
De qualquer modo, permanece escasso o número de trabalhos que dissertam sobre como realizar uma pesquisa psicanalítica. ${ }^{1}$

É importante salientar ainda que este artigo é apenas uma resposta possível, necessária, mas não suficiente à pergunta que lhe dá título e que, por isso mesmo, não é a única. Não se trata, portanto, de uma contribuição definitiva nem de uma orientação absoluta. É um recorte do modo como este autor se apropriou do método freudiano de pesquisa e nada mais que uma tentativa de sugerir uma sistematização aproximada que poderá servir de inspiração aos que desejam situar suas pesquisas sob a égide da tradição freudiana de investigação e procuram algumas referências na literatura nacional. Assim sendo, o que se propõe aqui pode servir como sugestão a qualquer trabalho que esteja comprometido com a psicanálise, não deixando de ser o esboço de uma nova orientação metodológica que não pretende ser a única, repito, mas que revela sua autenticidade pela singularidade de sua apropriação e, mais ainda, pelas imperfeições que, inevitavelmente, irá apresentar.

A pesquisa psicanalítica, justamente por trabalhar com a impossibilidade de previsão do inconsciente, não poderia jamais exigir uma sistematização completa e exclusiva. Sabemos que o trabalho de análise, em especial quando forma um analista, prioriza o estilo e a marca singular daquele que se coloca como analista para um outro. Assim é com a pesquisa psicanalítica. Ela é sempre uma apropriação do autor que depois de pesquisar o método freudiano descobre um método seu, filiado a essa vertente e o singulariza na realização de uma pesquisa.

A exposição que se segue é o resultado de uma apropriação. E como tal pode servir como operador de outras e novas apropriações. Como salienta Nasio (1997), as palavras do analista que profere um seminário ou escreve sobre sua prática podem transformar a prática de outros analistas.

\section{A SINGULARIDADE DA PESQUISA PSICANALÍTICA}

Diferentemente das estratégias metodológicas sugeridas pelas abordagens quantitativas e qualitativas de pesquisa, nossa proposta metodológica seguirá um rumo particular. A pesquisa psicanalítica marca sua diferença em relação às demais abordagens pelo menos em dois pontos fundamentais: primeiro, porque ela não inclui em seus objetivos a necessidade de uma inferência generalizadora, seja para a amostra ou para a população, pois seus resultados modificam a maneira como os pesquisadores da comunidade psicanalítica irão demarcar sua posição em relação aos novos sentidos produzidos pelo texto que torna a pesquisa pública; segundo, por-

\footnotetext{
${ }^{1}$ Podemos citar alguns dos trabalhos que, excetuando os textos de Freud e Lacan, que são de uma abordagem indireta, oferecem também suas tentativas de sistematização da pesquisa psicanalítica: CAON, 1994, p. 145-174; SILVA, 1993.
} 
que suas estratégias de análise de resultados não trabalham com o signo, mas sim com o significante, como veremos adiante. A seguir, então, apresentaremos uma revisão abreviada sobre o modo como a pesquisa psicanalítica serve-se do significante. O exame será elementar em alguns aspectos de modo a favorecer e alcançar um espectro amplo de leitores, desde os neófitos até os já iniciados.

\section{O SIGNIFICANTE NA PESQUISA PSICANALÍTICA}

Para Saussure (1990), o signo não une uma coisa e uma palavra como se observa no uso da língua, que está reduzida a seus princípios essenciais. O signo une um conceito a uma imagem acústica. A imagem acústica não é o som material, puramente físico, mas uma impressão psíquica desse som, a representação desse som para nossos sentidos. O signo lingüístico é, para Saussure (1990), uma entidade psíquica de duas faces, as quais são dependentes pois uma reclama a outra em sua íntima ligação.

Para Saussure (1990) o signo possui quatro propriedades. Primeiro, sua arbitrariedade, isto é, o signo é arbitrário para o conjunto de signos de uma determinada comunidade lingüística:

“a palavra arbitrário não deve dar a idéia de que o significante depende da livre escolha do sujeito falante. (...) Queremos dizer que ele é imotivado, isto é, arbitrário em relação ao significado, com o qual não tem nenhuma ligação natural na realidade." (SAUSSURE, 1990, p.83)

Segundo, uma vez escolhido o significante em uma comunidade lingüística, ele irá se impor a essa comunidade, à “massa falante” (Idem). É nesse sentido que o signo será imutável. Todavia, a convenção arbitrária que estabelece o caráter imutável do signo está ligada à tradição dele em determinada comunidade lingüística. Mas é por essa mesma tradição, que inclui a dimensão do tempo, que o signo poderá, paradoxalmente, sofrer certas alterações.

É o que, em terceiro lugar, evocaremos como alteração do signo:

“A alteração do signo é o resultado da prática social da língua ao longo do tempo. Se é por ser imutável que o signo lingüístico pode perdurar, é também por perdurar no tempo que ele pode alterar-se. Estamos diante de uma relação de reciprocidade contraditória entre imutabilidade e mutabilidade." (DOR, 1993, p.33)

A alteração do signo age no nível do significante através de uma alteração fonética e no nível do significado através de uma modificação do conceito. Há na alteração do signo um deslocamento da relação entre significante e significado (SAUSSURE, 1990). Por último, há o caráter linear do significante. A alteração do 
signo está ligada diretamente à prática da língua no tempo. O significante é uma seqüência fonemática que se desdobra no tempo (DOR, 1993). A fala presentifica o desenrolar temporal do significante: “com efeito, a língua desdobra-se numa direção orientada que chamamos de o eixo das oposições ou eixo sintagmático. É esta seqüência orientada que Lacan designa como cadeia significante” (Idem, p.33). Para finalizar, lembremos que a língua pode ser examinada de acordo com duas dimensões: a sintagmática e a paradigmática. Jakobson (1963) nos diz que falar implica em duas séries de operações simultâneas: a seleção de certo número de unidades lingüísticas no léxico e a combinação das unidades lingüísticas escolhidas. A seleção impõe a escolha de um termo entre outros e a combinação, uma articulação das unidades lingüísticas que se estabelece em certa ordem, indo do fonema ao semantema, passando pela palavra até chegar à frase. Assim:

“pode-se definir dois eixos que dividem a linguagem em sua totalidade, segundo o plano da seleção (eixo paradigmático) e segundo o eixo da combinação (eixo sintagmático). Deparamo-nos então, imediatamente, com a distinção (...) de Saussure entre língua e fala. Na medida em que as duas dimensões participam da linguagem, cada uma opera segundo um dos dois eixos. O eixo das seleções diz respeito ao sistema da língua enquanto escolha lexical; o eixo das combinações está ligado à fala enquanto utilização dos termos lexicais escolhidos. Eis aí uma das razões que conduziram Jakobson a considerar o sistema da linguagem em função do modo pelo qual os termos se encontrem associados: por similitude ou por contigüidade." (DOR, 1993, p.34)

Assim sendo, o discurso se desdobra em duas linhas: no eixo das operações metafóricas (eixo das seleções) e no eixo das operações metonímicas (eixo das combinações). Neste ponto podemos evocar os trabalhos de Lacan com o significante. A metáfora e a metonímia nos levam à “idéia fundamental de Lacan da supremacia do significante e as suas conseqüências com relação às formações do inconsciente" (DOR, 1993, p.35). Nesse ponto de nossa exposição é preciso que retomemos o problema do valor do signo, introduzido por Saussure e retomado por Lacan. A uma mesma imagem acústica articulada podem se ligar dois significados, produzindo duas significações diferentes. No exemplo de Saussure (1990, apud DOR, 1993) vemos isso de modo claro: Eu aprendo - Eu a prendo.

É o contexto da cadeia falada que irá circunscrever a significação, ou seja, o contexto irá delimitar a significação, estabelecendo o sentido. O contexto é um conjunto de outros signos e a realidade do signo só existe em função dos outros signos. Isso nos permite antever a noção de valor do signo (DOR, 1993). Para Saussure (1990) há um "corte" incidindo sobre o fluxo de pensamentos e sobre o fluxo de sons, que forma a cadeia falada onde a linguagem se estabelece por uma série de divisões: "uma idéia se fixa num som, ao mesmo tempo que uma seqüência 
fônica se constitui como significante de uma idéia” (Idem, p.38). O que para Saussure (1990) orienta a formulação do signo lingüístico: s/S.

Ao passo que para Lacan (1998), o signo recebe em sua formulação uma característica ligada à supremacia do significante: $\mathrm{S} / \mathrm{s}$.

Lacan (1998), com a noção reformulada acima, nos fala da supremacia do significante e não mais aceita a noção de "corte”, introduzindo um conceito original para a delimitação do signo: a noção de ponto-de-estofo. Esta inovação, segundo Dor (1993), é provocada pela experiência analítica, a qual demonstra que a relação do significante com o significado é sempre fluida, sempre prestes a se desfazer, exatamente como na experiência psicótica. O ponto-de-estofo é uma operação em que o "significante detém o deslizamento, de outra forma indeterminado e infinito, da significação” (LACAN, 1966, apud DOR, 1993, p.39). No esquema de Lacan, o vetor delta S barrado materializa o ponto-de-estofo, “colchetando” em dois pontos, segundo Dor (1993), a cadeia significante SS’. Há uma analogia possível com o "corte” de Saussure (1990) em que uma série de cesuras simultâneas determinam a significação. Para Lacan (1966, apud DOR, 1993), no entanto, a delimitação da significação fica circunscrita ao conjunto da seqüência falada e não a unidades elementares sucessivas. O ponto-de-estofo possui uma função diacrônica na frase, já que a significação somente pode ser dada com o último termo, e cada termo é antecipado na construção dos outros e sela, inversamente, seu sentido através de um efeito retroativo. Assim:

"Identificamos aqui uma referência direta ao problema do valor do signo analisado por Saussure. Cada signo só é significativo na relação de oposição que mantém com todos os outros signos da seqüência falada. Podemos adiantar, portanto, como faz Lacan, que é sempre retroativamente que um signo faz sentido, na medida em que a significação de uma mensagem só advém ao final de sua própria articulação significante. Esta dimensão retroativa do sentido é materializada no esquema do ponto-deestofo pelo sentido retrógrado do vetor delta S barrado; dito de outra forma, é na dimensão da posterioridade que o ponto-de-estofo detém o deslizamento da significação. A ambigüidade do problema da enunciação fica suspensa, em grande parte, a esta delimitação da significação na posterioridade da articulação.” (DOR, 1993, p.40)

O ponto-de-estofo da cadeia falada e sua transposição para a cadeia escrita será, alhures, o tema de nossa exposição sobre o método. O ponto-de-estofo será dado pela leitura dirigida pela escuta e pela instrumentalização da transferência, que examinaremos mais adiante.

Para esclarecer, assim, o trabalho da pesquisa psicanalítica com o significante e não com o signo, tomaremos por base as considerações de Juranville (1986). Segundo o autor, há que lembrar, em primeiro lugar, que “o inconsciente ultrapassa 
radicalmente o mundo como correlato necessário da consciência” (p.22). Assim, o contexto de uma antecipação ligada, portanto, ao domínio do signo lingüístico não serve para exprimir nem a hipótese nem a experiência do inconsciente, estas sobre as quais a pesquisa psicanalítica deseja realizar algumas aproximações. Os signos, que exprimem significações, estão ligados intrinsecamente ao "mundo”. O significante, tal como o apresenta Lacan, ultrapassa o mundo da experiência vivencial, que Husserl (1990) presume atrelado à experiência da consciência. Desta forma, o “mundo”, segundo Juranville (1986), se apresenta como um conjunto de signos. Melhor dizendo: como um mundo caracterizado pela presença de signos nele.

O signo traz um conhecimento do mundo: nuvens negras, presença de chuva. Mas esse conhecimento trazido pelo signo é, antes de mais nada, pressuposição, algo intuído de acordo com uma determinada lógica, que pode ser dedutiva, indutiva, etc. Mas quando se trata do inconsciente, que está estruturado como linguagem, o signo não pode garantir a destinação de algo que "deveria ser significado para o sujeito" (JURANVILLE, 1986, p.38). Ao contrário, o signo marca, justamente, com a primazia de um significado que se antecipa ao sujeito, a clausura desse sujeito na realidade de um mundo ligado à consciência. Lacan, segundo Juranville, quer avançar no plano de uma linguagem em que nada aparece além do significante. Um significante puro, o qual, ainda assim, não impede uma associação com determinado significado. Só que esta associação não será única, como no sistema de Saussure, mas múltipla e até caótica, como no caso da psicose. O significante, então, será diferente do signo - que está necessariamente ligado à realidade do mundo — pois só é significante para determinado sujeito em determinada situação. É isso que Lacan (1998) quer dizer com sua afirmação de que um significante representa um sujeito para outro significante.

O significante lacaniano "é o inconsciente enquanto recorre a uma outra ordem que não a do mundo — o sintoma, por exemplo” (JURANVILLE, 1986, p.49). Isto posto, o sintoma, a alucinação, o sonho, enfim, as formações do inconsciente não podem mais ser qualificadas de "representações". O essencial, conclui Juranville, é sublinhar que a representação de coisa é tal, em si mesma, que tem um objeto inconsciente, o qual faz com que o diverso sensível que a constitui encontre um sentido, isto é, seja significante para o sujeito. É no sentido dessa experiência, que é significante para o sujeito e desligada da antecipação prevista pelo signo, que a pesquisa psicanalítica deseja encontrar suas formulações essenciais.

\section{O DELINEAMENTO DA PESQUISA PSICANALÍTICA}

O primeiro ponto a ser destacado é o modelo em que se baseia o pesquisador psicanalítico. Esse modelo nos é dado pelo analisante, o qual realiza, no divã, a pesquisa da vida. A pesquisa do analisante é dirigida pelo analista, que o faz através 
da técnica psicanalítica específica da situação de tratamento. Todavia, frisemos desde já que ao adotarmos esse modelo isso torna desde logo o pesquisador psicanalítico o primeiro sujeito de sua pesquisa. Pois assim como o analisante se engaja no processo de análise e diz algo de seu padecimento psicopatológico, inserido em uma situação de transferência, o pesquisador psicanalítico dá um testemunho de sua investigação a um outro, a uma alteridade com a qual também irá se “transferenciar". Neste caso, da pesquisa psicanalítica, tanto o dado de pesquisa como aqueles a quem o pesquisador destina sua pesquisa podem ocupar este lugar de alteridade. ${ }^{2}$

Ora, quando tomamos o analisante como arquimodelo do pesquisador psicanalítico e dizemos que este último está implicado como primeiro sujeito de sua pesquisa, não o fazemos por capricho ou para instituir um paradoxo. Dizer que o pesquisador psicanalítico é o primeiro sujeito de sua pesquisa significa dizer que ele está também implicado como um participante importantíssimo na investigação realizada. É claro que isso não dispensa os demais participantes da pesquisa, mas admitir que não há uma implicação do pesquisador como sujeito seria absurdo, já que é pelo punho do pesquisador que uma contribuição conceitual vai se organizar durante o processo de pesquisa. Assim sendo, já podemos traçar algumas linhas fundamentais para o entendimento da pesquisa psicanalítica e seu método a partir da seguinte concepção:

“A característica essencial que singulariza o pesquisador psicanalítico é o campo, o objeto e o método de sua pesquisa. Este campo é o inconsciente. O objeto é o enfoque ou perspectiva a partir de uma posição em que é colocado o pesquisador psicanalítico, a fim de aceder ao inconsciente. O método é o procedimento pelo qual ele se movimenta pelas vias ou perspectivas de acesso ao inconsciente." (CAON, 1994, p.23)

Definimos, assim, o campo e o objeto da pesquisa psicanalítica, mas podemos ir adiante na concepção do método. O método da pesquisa psicanalítica somente pode ser compreendido a partir daquilo que denominamos como situação psicanalítica de pesquisa (SPP), a qual deve ser examinada à luz da situação psicanalítica de tratamento (SPT), pois é desta que retira seu modelo (CAON, 1994). A transferência é a característica identificatória da SPP a partir do modelo da SPT. O que irá distinguir estas duas situações será o destino dado à transferência em cada uma delas. Em se tratando da SPT, a transferência será dissolvida; na SPP, entretanto, a

\footnotetext{
${ }^{2}$ A alteridade é o outro a quem se destina algo, podendo ser o analista a quem se destina a transferência, no caso da situação psicanalítica de tratamento, podendo também ser o público, no caso da situação psicanalítica de pesquisa, a quem se destina o texto da investigação realizada.
} 
transferência será instrumentalizada para a produção de um texto metapsicológico (CAON, 1994). São duas as noções que irão embasar os dispositivos metodológicos da pesquisa psicanalítica: solipsismo e alteridade. Destas duas noções é que partirão os demais procedimentos metodológicos do pesquisador psicanalítico. Contudo, é preciso que situemos, antes de examinar tais dispositivos, o vocábulo “experiência” em suas principais acepções na língua alemã: Experiment, Erlebnis e Erfahrung. No Experiment temos a experiência propriamente dita do cientista em seu laboratório. Nela, o experimentador e sua vivência desaparecem perante o objeto. Erlebnis é a vivência do sujeito, na qual o objeto desaparece perante o experimentador. Erfahrung, por fim, indica uma experiência que se transformou em aprendizado e saber (LAPLANCHE, 1987). Erfahrung é o sentido da experiência que interessa ao pesquisador psicanalítico, pois sua investigação é da ordem de uma aprendizagem. Quando o pesquisador psicanalítico realiza sua investigação, o faz de modo que não apenas cite e recite teorias para em seguida validar suas aplicações empíricas; sua meta é de maior alcance: trata-se de problematizar um aspecto do campo psicanalítico e oferecer uma contribuição que não seja limitada pela confirmação da teoria.

O pesquisador psicanalítico está engajado em um processo de descoberta, de revelação ou mesmo de renovação de seu campo. Por isso a experiência no sentido da Erfahrung nasce do solipsismo e da inclusão de uma alteridade (CAON, 1994). O solipsismo em questão nos procedimentos da pesquisa psicanalítica é o chamado solipsismo metodológico, isto é, um solipsismo que conserva apenas a forma e não o conteúdo da concepção tradicional de solipsismo (CAON, 1994; CARNAP, 1929). Há nele uma concepção particular que rompe de certa forma com o solipsismo tradicional, já que permite um avanço ao entender que a base do solipsismo, ou seja, uma experiência subjetiva elementar, somente poderá ser caracterizada como “minha” em uma etapa posterior à constituição dos conceitos, quando entram em cena simultânea e solidariamente as noções de ego e alter ego (CAON, 1994; BOUVERESSE, 1987).

A noção de solipsismo metodológico que examinamos aqui revela sua importância ao ressaltar a necessidade do outro que serve ao sujeito que fala ou escreve de audiência benevolente e benfazeja como no caso de Freud e Fliess (CAON, 1994). Assim, sua importância não está desvinculada de uma alteridade a que possa se dirigir o pesquisador psicanalítico. Já vimos que o solipsismo metodológico não é uma espécie de solipsismo, mas um método de construção de conceitos (SCHLICK, 1936; BOUVERESSE, 1987), o que nos permite entender a metapsicologia, ou a derivação de conceitos em psicanálise da mesma forma, ou seja, como um método de pesquisa no qual a fantasia da construção de conceitos está submetida a uma crítica impiedosa por parte da realidade (CAON, 1994).

Quando falamos de solipsismo metodológico, é necessário uma aceitação do 
outro, da alteridade. Na SPT, o analisante necessita de uma alteridade objetiva representada pelo psicanalista. Na SPP é o modelo da pesquisa de Freud que vai nos guiar em nossa construção de uma metodologia. Introduziremos, assim, as noções de Publikum e Öffentlichkeit (CAON, 1994). Observemos que Freud, ao começar suas pesquisas, dirige-se a Fliess, o qual acolhe os primeiros escritos freudianos in status nascendi. Em outro momento, Freud entrega seus achados a um público anônimo, de quem não recebe resposta alguma. A alteridade representada por Fliess é lugar do Publikum e o público anônimo que fica indiferente às pesquisas freudianas é o lugar do Öffentlichkeit. Aqui nos interessa mesmo é o lugar do Publikum, que depois será retomado por Freud nos Serões Psicológicos das Quartas-feiras, onde se reuniram os primeiros pesquisadores psicanalíticos, ouvintes e colaboradores de Freud (CAON, 1994). Assim, o Publikum é o lugar da alteridade convidada a examinar os achados da SPP e é a esta noção que vamos entregar os dados coletados a partir de nossa investigação. O Publikum localizado no lugar do outro que acolhe os achados metapsicológicos é, sobretudo, lugar de uma audiência benfazeja e crítica (CAON, 1994).

Há ainda uma outra característica importante para esse outro da pesquisa psicanalítica. Para caracterizá-lo utilizaremos o modelo do Einsicht. ${ }^{3}$ Quando o pesquisador psicanalítico apresenta seu achado metapsicológico ao Publikum escolhido como alteridade, há uma ressonância representada pelo maravilhamento e pela edificação deste achado que causam na mente do outro. A fulguração do discernimento (Einsicht) é a ressonância do achado metapsicológico no espírito do outro (CAON, 1994). A relação do pesquisador psicanalítico com esse outro, audiência benfazeja e crítica, irá permitir a construção do trabalho metapsicológico de pesquisa. Chamamos esse trabalho de perlaboração (Durchabeiten), o qual se realiza a partir de um padecimento, de uma paixão, de um amor, que é padecimento de transferência. Por isso a necessidade de uma alteridade na SPP (CAON, 1994).

\section{PROCEDIMENTOS PARA COLETA DE DADOS}

O primeiro e principal participante de uma pesquisa psicanalítica é o seu próprio autor. Todavia, ele pode contar ainda com colaboradores que serão participantes da pesquisa. O método da pesquisa psicanalítica não traz inovações quanto à escolha dos sujeitos ou participantes, nem mesmo apresenta alguma peculiaridade quanto aos procedimentos para coleta de dados ou mesmo aos instrumentos e materiais empregados. Tais etapas metodológicas ficam a critério da criatividade do pesquisador. O que podemos introduzir como novidade são os dispositivos metodológicos utilizados nos procedimentos de análise dos dados. Outra maneira

\footnotetext{
${ }^{3}$ Discernimento, em alemão.
} 
de o pesquisador psicanalítico obter seu dado é convidando seus colaboradores à produção textual: os participantes recebem o convite de produzir um texto escrito sobre a temática pesquisada.

Os procedimentos para coleta de dados podem ser realizados através de entrevistas gravadas em áudio e/ou vídeo. Também fragmentos ou versões integrais de sessões clínicas transcritas podem ser dados para uma pesquisa psicanalítica. Histórias clínicas, biografias e autobiografias literárias, bem como obras de arte (cinema, pintura, fotografia, escultura, literatura, etc.) podem servir ao pesquisador psicanalítico. A coleta pode ainda utilizar-se de material clínico propriamente dito. O diário clínico é outra forma que podemos observar em Ferenczi (1993) e na correspondência entre Freud e Fliess. O mais importante é que o pesquisador transforme sempre seu dado em texto. Além disso, há o diário metapsicológico de campo. Uma proposta para iniciar a produção escrita da pesquisa já em sua chegada ao campo. Vejamos quais são seus fundamentos epistemológicos.

\section{O DIÁRIO METAPSICOLÓGICO DE CAMPO DE IRIBARRY}

Os três eixos epistemológicos do diário metapsicológico de campo são a pesquisa etnológica ou a etnografia, a observação participante e o diário clínico. Quando vamos a fundo na literatura sobre etnografia e pesquisa de observação participante, descobrimos uma situação problemática. Há uma confusão sobre a delimitação dos conceitos e sobre a geração e a aplicação dos métodos. Para evitarmos discussões ad infinitum, selecionamos, para a etnografia e a pesquisa de observação participante, autores cuja focalização dos temas nos pareceu objetiva e livre de imprecisões.

Segundo Mauss (1947), a pesquisa etnológica consiste numa observação das sociedades e dos fatos sociais destas. A etnografia seria, portanto, uma estratégia metodológica em que a observação é o recurso mais importante. Através da observação, uma vez inserido em seu campo de investigação, o pesquisador delimita seu estilo de observação e o estilo de registro que irá utilizar. Para Mauss (1947), tais estilos podem ser morfológicos, cartográficos, fotográficos, fonográficos, filológicos e sociológicos. Para nosso diário metapsicológico de campo selecionaremos os dois últimos.

Para compor seu diário, o pesquisador psicanalítico registra línguas e linguagens (estilo filológico) e se atém ao modus vivendi (estilo sociológico) do campo em que está inserido (MAUSS, 1947). Há também o trabalho precursor de Malinowski (1937/1976), em que encontraremos uma espécie de sistematização a posteriori dos trabalhos do antropólogo. O segundo eixo epistemológico é a pesquisa com observação participante. Para Gutierrez \& Delgado (1995), a observação participante consiste num mergulho radical no campo do objeto de pesquisa, no qual o 
pesquisador aparece como um estrangeiro. Ao longo deste mergulho, o pesquisador inicia uma monografia etnográfica e uma auto-observação, as quais são registradas em um diário. Tal diário, na perspectiva de seu terceiro eixo epistemológico, será clínico.

Nossa concepção de diário clínico está apoiada em Ferenczi (1993) e na correspondência entre Freud e Fliess. O diário clínico permite que o pesquisador deixe fluir associações significantes formando uma trama, um tecido textual, em que sua experiência fica registrada. Podemos aludir ainda aos Breves escritos de Freud (1938). No pequeno trabalho, encontramos algumas anotações aleatórias em forma de fragmentos. Anotações que talvez reflitam um dos estilos de trabalho de Freud, ou seja, reunir pequenos registros e idéias para aproveitamento posterior. De posse dos dados coletados, o pesquisador psicanalítico converte o dado em texto e parte para os procedimentos de análise de dados. E são nos procedimentos de análise dos dados que as noções enumeradas acima tornar-se-ão dispositivos metodológicos. Nos procedimentos de análise dos dados, o pesquisador psicanalítico encaminha-se para a produção do ensaio metapsicológico.

Mas quais os procedimentos propriamente ditos para examinar os dados quando se trata de uma pesquisa psicanalítica? Quando os dados já estiverem coletados, o pesquisador psicanalítico se lança à leitura dos dados, organizados em forma de texto escrito. No caso de entrevistas, por exemplo, estas serão transcritas para juntamente com os textos coletados serem lidas pelo pesquisador. Todavia, não é uma leitura pura e simples dos dados que vai fornecer subsídios para a construção do ensaio metapsicológico, mas sim uma leitura que se faz à luz de duas técnicas psicanalíticas de interpretação dos dados. São elas: a leitura dirigida pela escuta e a transferência do pesquisador ao texto dos participantes da pesquisa (CAON, 1994; FÉDIDA, 1992).

\section{A ESCUTA DIRIGIDA PELO OLHAR E A LEITURA-ESCUTA}

A escuta dirigida pelo olhar é um dispositivo clínico de que o psicanalista dispõe para dirigir o tratamento. Uma escuta, na clínica psicanalítica está ligada a uma via de mão dupla: por um lado, o psicanalista escuta apoiado na teoria e, por outro, fica atento ao desfile de significantes que o analisante realiza com sua fala (CAON, 1996).

Para isso que se chama leitura-escuta, nada melhor que evocarmos as palavras daquele que cunhou o termo:

“Mas o saber ler é necessário sob vários pontos de vista para a escuta. Primeiramente, pela particularidade da escuta analítica, que de forma alguma se trata do puro efeito sensorial de ouvir; trata-se efetivamente de leitura-escuta. Pois se, por um lado, a 
escuta pode situar-se num material sonoro, a leitura diferentemente, dá-se a partir de um texto, de uma escrita, de uma escritura. E se o material sonoro é dado no dito, sob a forma de palavras, de enunciados, a enunciação é uma leitura que busca encontrar o suporte mesmo do falar na relação analítica. Por isso a metáfora da leitura, pois é lendo na escuta que podemos sacar o ponto de um equívoco, de uma suspensão; ou seja, aquilo que desvela a própria enunciação.” (SOUZA, 1988, p.117)

\section{A LEITURA DIRIGIDA PELA ESCUTA COMO PROCEDIMENTO DE ANÁLISE DOS DADOS}

A leitura dirigida pela escuta é sempre tributária de uma escuta dirigida pelo olhar. Assim, o pesquisador psicanalítico vai instrumentalizar sua transferência ao texto composto pelo dado coletado de modo que possa identificar significantes já escandidos pelo autor do texto como também efetuará um trabalho de escansão de significantes que a legibilidade do texto permite. O trabalho de leitura dirigida pela escuta psicanalítica é o que caracteriza o laboratório do texto psicanalítico, quando o pesquisador irá construir o ensaio metapsicológico. Há um trabalho de leitura dirigido pela escuta, em que o pesquisador procura identificar, de modo semelhante à clínica, as falhas e tropeços de um discurso realizado, neste caso, através da escrita (CAON, 1996). Além disso, o pesquisador psicanalítico é movido por suas impressões transferenciais sobre o texto examinado e fica atento ao desfile dos significantes que o compõem, procurando estabelecer uma teoria em gérmen, uma construção de natureza ficcional (FÉDIDA, 1992), na qual o ensaio metapsicológico é o objetivo final.

Estas impressões transferenciais resultam do modo como o pesquisador faz sua leitura dos dados, o que faz com que surja a pergunta: mas, então, o pesquisador psicanalítico é movido por sua subjetividade ao analisar o dado de pesquisa? Sim, esta é a contribuição mais legítima que podemos extrair do percurso de Freud, pois este sempre esteve movido por suas inclinações pessoais diante dos dados de sua pesquisa, e foi graças à sua interferência subjetiva que a psicanálise nasceu como uma teoria, um método e uma técnica de tratamento (FÉDIDA, 1992). Mas antes de passarmos ao ensaio metapsicológico, é necessário que façamos outra digressão. É preciso que introduzamos uma aplicação original da noção de pontode-estofo de Lacan.

\section{O PONTO-DE-ESTOFO DA CADEIA ESCRITA}

Quando o pesquisador psicanalítico converte seu dado em texto é guiado pela transferência instrumentalizada e pela leitura dirigida pela escuta, incluindo também suas implicações subjetivas, o objetivo é compor o ensaio metapsicológico. Mas para chegar à esta etapa, que examinaremos a seguir, é preciso que um trabalho sistemático seja realizado com os significantes que compõem o texto. Este tra- 
balho é uma escansão da cadeia escrita e a introdução de um ponto-de-estofo na cadeia escrita que o texto representa. São os significantes introduzidos pela experiência do pesquisador com o texto que irão oferecer novas significações, novos sentidos para o dado coletado e transformado em texto. A responsabilidade é inteiramente do pesquisador psicanalítico e cada termo novo acrescentado ao texto e divulgado pelo ensaio metapsicológico alarga o horizonte de compreensão e explicação da temática investigada.

Os resultados dessa investigação serão organizados a partir dos procedimentos para análise dos dados. Neles, serão utilizadas as técnicas já apresentadas antes: a leitura dirigida pela escuta e a transferência instrumentalizada. Além disso, as noções de solipsismo metodológico, alteridade e Erfahrung acompanharão todos os procedimentos de análise dos dados, de modo a lhes servir também como dispositivos metodológicos. Quando o pesquisador psicanalítico dirige-se ao texto que seu dado representa, ele o faz já tendo sido constituído pela ação de significantes que lhe permitem estar situado como sujeito em relação a outros significantes, como já nos dizia Lacan (1998) — o significante representa um sujeito para outro significante. O pesquisador psicanalítico dá escuta para o texto (leitura-escuta) e produz a partir desta experiência uma capacidade de transformação metapsicológica, conforme já vimos. A comunicação desta experiência de transformação metapsicológica é também uma experiência científica:

\footnotetext{
“Uma comunicação científica é, dentro de suas possibilidades contextuais, trazer para a meditação partilhada, numa comunidade de linguagem, os ecos de um processo de pensamento, de um trabalho. Supõe-se que ele possa estar em contínua e frutífera interação com seus pares." (PETRY, 1993, p.2)
}

\section{PROCEDIMENTOS PARA ANÁLISE DOS DADOS}

De posse dos dados coletados, eles serão examinados, inicialmente, levando em consideração as noções de solipsismo metodológico e alteridade, já detalhadas antes. O solipsismo metodológico é uma forma de solipsismo em que não se fica restrito ao âmbito de uma experiência subjetiva elementar e única, mas, ao contrário, se convoca uma alteridade para comunicação desta experiência. O pesquisador vai comunicar sua experiência ao público (alteridade) a que sua pesquisa se destina. Esta alteridade é o outro a que se dirige o pesquisador, no caso, o público. Este público divide-se em intermediário (banca examinadora) e anônimo (futuras publicações). Como já vimos, o primeiro relaciona-se com a noção de Publikum e o segundo com a noção de Öffentlichkeit.

A experiência do pesquisador psicanalítico diante das entrevistas e questionários respondidos é tomada no sentido de uma aprendizagem que se transformou em saber, ou seja uma Erfahrung. A Erfahrung é a experiência que decorre do contato 
do pesquisador com os participantes de sua investigação e com os dados coletados. Ao realizar sua investigação, o pesquisador psicanalítico está modificado por uma experiência que começou com o estabelecimento de um problema de pesquisa, com a escolha de uma estratégia para abordá-lo, e que irá culminar com a construção do ensaio metapsicológico. Ao realizar as entrevistas e aplicação de eventuais instrumentos, o pesquisador psicanalítico está tomando parte em uma experiência de aprendizagem, da qual é impossível subtrair as interferências de seu espírito diante dos dados que recolhe.

Para comunicar sua Erfahrung, ou seja, a experiência que decorre dos procedimentos para coleta de dados, o pesquisador psicanalítico utiliza técnicas específicas para tratamento dos dados: a leitura dirigida pela escuta e a transferência instrumentalizada. Uma leitura dirigida pela escuta é o dispositivo com o qual o pesquisador identifica, no texto transcrito das entrevistas e questionários respondidos por seus colaboradores (sujeitos participantes de pesquisa), contribuições singulares e diferenciadas daquelas que a literatura fornece, procurando identificar significantes cujo sentido assumem o caráter de uma contribuição para o problema de pesquisa norteador da investigação.

A transferência instrumentalizada é o processo por meio do qual o pesquisador se dirige ao dado de pesquisa situado pelo texto dos colaboradores e relaciona seus achados com a literatura trabalhada e procura, além disso, elaborar impressões que reúnem as suas expectativas diante do problema de pesquisa e as impressões dos participantes que forneceram suas contribuições na forma de dados coletados. Esta técnica de análise dos dados se baseia em uma leitura dos textos, de onde o pesquisador retira subsídios para a composição do ensaio metapsicológico. Não há manipulação dos signos (como na análise de conteúdo e na análise do discurso), fica-se restrito ao domínio do significante e da abertura de sentidos que lhe é característica. Nessa abertura, o pesquisador situa os significantes de suas expectativas em relação ao tema de pesquisa. Assim, o pesquisador psicanalítico prepara-se para a construção do ensaio metapsicológico, texto que irá compor a parte de discussão dos dados de modo a preparar as considerações finais do trabalho.

\section{O ENSAIO E O ENSAIO METAPSICOLÓGICO}

A forma do ensaio é irmã da literatura. A ficção é o ponto de partida e o ponto de chegada do ensaísta. Entre os dois pontos está a experiência. Mesmo que o objeto da experiência exija um relevo fundamental, o sujeito não se retira da cena: ele mescla subjetividade e objetividade em seu movimento. De sua implicação de sujeito, o autor da experiência procura a vivência de algo concreto, mas repleto de fantasias, às quais põe em diálogo com a alteridade. De sua implicação objetiva, o autor da experiência busca uma aprendizagem com e a partir da vivência. Por isso, 
o ensaio reúne o território da irracionalidade artística com o de uma ciência organizada para a produção do conhecimento. Assim, o ensaio implica liberdade de espírito. O espírito livre não sacrifica todas as convicções em favor de uma única como faz a ciência; o prelúdio positivista deseja afirmar a convicção de que o espírito científico não admite convicções e sacrifica todas elas em favor desta.

O espírito livre é arrojado: enfrentará a possibilidade de naufrágio de sua fantasia; todavia, ainda assim lhe restam as possibilidades de triunfo e de uma nova exploração graças ao timoneiro chamado alteridade. O ensaio retoma o ócio infantil e o entusiasmo pelo já feito. Como o poeta efebo que goza a influência de seu mestre até encontrar a liberdade de sua letra e viver uma angústia cuja influência é a de não poder não escrever, mas agora como autor singular. O ensaio termina quando encontra o fim, quando é abandonado, pois se estanca para não prosseguir no que está dizendo, sendo esta a hora de uma alteridade anônima verificar sua demonstração.

O ensaio reflete, não contenta, não classifica. Possui uma inteligência desviada: delira e inventa coisas onde nada há. É a ficção que lhe serve de sangue, buscando o domínio da invenção, da criatividade diante do já feito, já visto, e também do nunca tentado. Reúne, portanto, o homem de fatos da ciência com o homem aéreo da poesia. Aceita o terror da proibição de dizer além do já dito (ADORNO, 1965). O ensaio possui uma autonomia estética e desconfia do modelo canônico e positivista de conteúdo. A consistência não brota da retirada do sujeito, de sua supressão em favor de uma quimérica neutralidade científica; ela brota justamente de sua inclusão e revela um autor em sua opacidade, na pior das hipóteses; ou, na melhor das hipóteses, um autor cuja clareza é cortesia de gênio.

Para o ensaísta, autônomo em sua estética, não existe alergia da forma, aquela do espírito científico dogmático e obstinado. Como na literatura de Proust, o ensaio traz à tona a sensibilidade do escritor que vai além da ciência e é capaz de enunciar conhecimentos profundos e sólidos sobre o homem e seu contexto social. Para Freud (1906, apud KOFMAN, 1995), o escritor, com sua sensibilidade, possui a coragem de deixar falar seu próprio inconsciente (a obra de arte é uma confissão do autor, mas é preciso saber lê-la) e a capacidade de perceber pulsões ocultas no espírito das coisas e das pessoas.

Os escritores desejam proporcionar prazer estético e intelectual através de efeitos emocionais. Assim, não podem re-produzir a matéria da realidade sem modificá-la. A ficção é audaciosa: mas a renúncia ao princípio do prazer, de que Freud (1910) diz ser a ciência a mais radical representante, é relativizada na forma do ensaio: toda ficção deverá ser corrigida pelo diálogo com a alteridade. E alteridade é princípio de realidade.

No ensaio, não há pretensão de objetividade; há uma vaga plausibilidade. Não interessa a verificação da tese defendida pela eficácia e repetição de sua comprovação. Interessa o conjunto da experiência individual e sua potência de vivência cria- 
dora e instauradora de aprendizagem. O ensaio quebra a continuidade das teorias empiristas elevando às últimas conseqüências a experiência não conclusiva e não antecipadora de uma ordenação conceitual fixa.

O ensaio não procura o eterno no passageiro, mas quer eternizar o passageiro. A vivência é o lance, fugaz, que prepara o segundo tempo: aquele de uma aprendizagem, relance do primeiro, em que o sujeito, livre do objeto, encontra sua capacidade de autoria. Demonstrando assim como aprendeu e ocupando o lugar de ensinante. $\mathrm{O}$ ensaio acaba com a ilusão de que o pensamento possa partir da thesei (cultura) para atingir a physei (natureza). A única ponte que reúne tese e natureza é a da ficção e quem testa seus alicerces é a alteridade.

O ensaio procede metodicamente através do não método. A figura de Adorno (1965) é mais que ilustrativa: o estrangeiro que aprende uma nova língua sem ir ao dicionário é um privilegiado que desfruta de uma palavra em diferentes contextos e, por isso, pode experimentar as diferentes nuances de sentido, as quais o dicionário, por maior que seja seu esforço, somente oferece um pálido reflexo.

Em última e provisória análise, o ensaio rompe com a tradição cartesiana de impor um percurso de aquisição de conhecimentos que vão dos mais simples aos mais complexos. O ensaísta não teme desafios, pois sabe que o simples é familiar; busca a complexidade de um autor, de um tema, seja o que for. O ensaio não tolera o engodo de que para entender o complexo é preciso primeiro cortejar o simples; o adiamento do desafio de uma compreensão acaba por impedi-la. O ensaio é como a vida: sempre inconclusivo para o seu autor, pois no dia de sua morte, apenas os que ficarem poderão falar do que restou, enquanto o autor jamais poderá extrair uma aprendizagem desta vivência radical e derradeira. Enquanto se vive, se pode ensaiar. Contudo é preciso saber que o espetáculo é o próprio ensaio e não haverá outra chance para cada ato, cada cena - o autor é ator de um drama singular, inadiável e intransferível.

O ensaio metapsicológico segue a tradição da metapsicologia freudiana, pois está situado como um texto produtor de modelos conceituais. Tais modelos afastam-se da experiência e constituem ficções teóricas a partir das quais a própria experiência é radicalmente transformada. Garcia-Roza (1996) nos dá uma idéia clara da metapsicologia freudiana:

"O termo ficção teórica pode causar estranheza. Afinal costumamos opor a liberdade imaginativa da ficção ao caráter rigoroso e restritivo da teoria. Mas, na verdade, produzir conceitos é inventar, é violentar o dado, ultrapassando-o.” (p.11)

Em carta a Fliess, Freud escreveu que sem especulação e teorização metapsicológicas — os quais aproxima da fantasia — não se avança na pesquisa psicanalítica. Freud costumava chamar a metapsicologia de "feiticeira", pois é ela que por 
meios nem sempre muito claros, pelos caminhos da imaginação, possibilita esse passo adiante no sentido da criação, arrancando o pesquisador da admiração do dado e ao mesmo tempo impedindo-o que o formalismo teórico o paralise. Caon (1994) fala-nos, então, do ensaio metapsicológico, texto que deve convocar uma alteridade para que a experiência do pesquisador seja comunicada.

Como já vimos no item relativo ao método, o ensaio metapsicológico é uma construção que deve surgir a partir da pesquisa realizada e apresentada à banca examinadora, de modo que, futuramente, dela surjam artigos destinados a um público anônimo. Esta é a perspectiva que adotaremos quando nosso trabalho estiver realizado. Por enquanto são estas as linhas que podemos fornecer acerca do trabalho de construção do ensaio metapsicológico, o qual deverá aparecer como um texto provisório sobre os resultados da investigação. Tal texto, após ter sido apreciado pela banca examinadora, suscitará no pesquisador uma série de idéias e modificações que o guiarão perante a produção de artigos ou mesmo durante os ensaios de uma pesquisa em nível de mestrado e/ou doutorado. Mas há também a construção do caso. A construção do caso é diferente do estudo de caso. Examinemos tais diferenças.

\section{O ESTUDO DE CASO}

De acordo com Stake (1994), o estudo de caso, como estratégia metodológica na pesquisa clínica, é entendido como resultado da comunicação de uma experiência, na qual o terapeuta escolhe uma situação de tratamento para desenvolver sua pesquisa. Esta experiência começa com o registro de apontamentos anamnésicos que irão compor uma história clínica e uma evolução das sessões realizadas em um determinado período de tempo. Em geral, o estudo de caso, após realizado, servirá como parâmetro para discussão de uma teoria subjacente à técnica utilizada na condução desta experiência de tratamento. No estudo de caso, há uma delimitação conceitual daquilo que servirá como objeto de investigação.

Nesta delimitação são selecionados fenômenos, temas ou questões norteadoras da pesquisa. As informações registradas pelo pesquisador são padronizadas e servirão para uma interpretação. Tal intenção pode tanto servir à teoria subjacente à técnica clínica examinada, como também pode servir de exemplo negativo para uma orientação teórica preestabelecida. A hipótese, no estudo de caso, apresenta uma possibilidade de descrição para uma realidade psicológica. Exemplifiquemos. O pesquisador pode escolher um fragmento de um atendimento clínico e, a partir de um comportamento explicitado pelo corpo ou pela fala do paciente, localizar um suporte para a descrição desta realidade psicológica. Esta realidade psicológica é, portanto, o resultado de uma abstração que o pesquisador faz do comportamento observado.

Para o pesquisador que se ocupa da realização de um estudo de caso, sua alteridade fundamental é a teoria. Talvez fosse melhor dizer que a teoria lhe serve de 
suporte e referencial para o desenvolvimento de sua hipótese e é com ela - a teoria - que ele irá dialogar. O estudo de caso apresenta um relato baseado na cronologia de fatos de uma história cuja narrativa se dá pela evolução do tratamento de um paciente. O relato do caso, bem como seu registro e discussão, serão tomados como dados de pesquisa e examinados, na etapa de análise dos dados, através de ferramentas metodológicas como a análise de conteúdo e a análise de discurso.

Para Allones (1989), o estudo de caso, bem como a comunicação dos resultados de uma pesquisa, possui cinco grandes variações. Em cada uma delas, o estudo de caso cumpre funções epistemológicas diferentes e se pauta através de métodos diversos em sua natureza. Em psiquiatria, seu emprego é originário e evolui da anamnese para a preparação do diagnóstico. Seu objetivo é compreender a doença, cuidar do paciente e formar uma representação semiológica e nosográfica. Em relação à psicopatologia, o estudo de caso presta-se para alargar o campo de explicação dos processos psicopatológicos e amplia a equação causalista da afecção psicopatológica e o comportamento do sujeito afetado.

Em psicanálise, o estudo de caso segue a pauta da psiquiatria, em que Freud, de modo paradigmático, instaura um estilo de relatar documentalmente a evolução de pacientes tratados por ele e que serviram, através de suas constelações biográficas e sintomáticas, como modelos para sua metapsicologia. A sociologia, por sua vez, adota técnicas que utilizam histórias de vida e de romance familiar, por exemplo, como meios de abstração do elemento social formador da subjetividade.

Por fim, na psicologia clínica, o estudo de caso despreza a avaliação e o diagnóstico e privilegia a evolução de uma biografia nos planos clínico e psicopatológico. Allones (1989) nos fala também das funções do estudo de caso. Segundo o autor, o estudo de caso gravita em torno de dois eixos fundamentais: informar e ilustrar. Com isso, surge, a partir de sua comunicação, uma problematização da teoria e uma tentativa de apoiar sua modificação ou sua confirmação. É interessante mencionar o modo como Allones (1989) trabalha a questão da informação e da ilustração. Para o autor, quando o estudo de caso, através da coleta de dados, evoca uma realidade que se transcreve como objetiva e a utiliza para uma ilustração daquilo que, na clínica, integra teoria e prática, não estaria ele produzindo apenas uma ilusão de realidade?

Em relação ao processo de construção do estudo de caso, Allones (1989) enumera seis aspectos essenciais para tal processo. Em primeiro lugar, encontramos a limitação trazida pelo próprio dado que servirá de mote ao estudo de caso. Por exemplo, quando uma adolescente gestante consulta um clínico geral e é encaminhada ao ginecologista. Segundo o autor, o pesquisador não pode extrapolar essa limitação sob pena de tomar seu estudo de caso inverossímil. Em segundo lugar, está a seleção ditada pelo olhar do pesquisador. Não se pode entrever tudo. O olhar 
do pesquisador seleciona, de alguma forma, o dispositivo que irá canalizar um aspecto que o caso permite desenvolver. Um terceiro ponto diz respeito à naturalização, já que o pesquisador naturaliza o dado de pesquisa e, dessa forma, se produz um discurso afastado do real do caso. Outro aspecto é a passagem do contínuo ao descontínuo: novamente, o autor se interroga sobre a produção de uma ilusão da realidade, a qual se daria através de um nível descritivo e informativo da realidade do caso para um momento descontínuo cujo impacto é a própria formulação que se faz do caso na teoria. Allones (1989) menciona ainda a redução como problema inevitável. Por mais singular que o caso seja, a teoria exige, confirmada ou não, uma perda: a perda do “vivido” como recurso necessário à sistematização metodológica.

Por último, vem o trabalho da escrita. Mas a que preço? Allones (1989) nos diz que a escrita do estudo de caso é uma síntese problemática. E que muitas vezes fica reduzida a uma objetividade que se apóia na teoria e, curiosamente, infere sentidos que não são objetivamente observáveis no caso examinado e estudado. Allones (1989) cita, com alguma malícia, uma tese de doutorado em que o autor destaca do prontuário de uma paciente a seguinte frase: "Em fevereiro, vê-se o Édipo da paciente Isabelle evoluir” (p.54). A partir disso, ressalta a importância de compreender que tal recorte não pode ser coadunado assim tão facilmente com a teoria. Ora, o que se observa é a conduta do paciente e isso não significa, absoluta e necessariamente, que o complexo edípico está em evolução. Sobre o que um estudo de caso pode inferir do particular ao universal, Allones (1989) não acredita em uma indução possível. A singularidade de cada caso é parte não só da experiência situada pelo paciente, mas também pelo pesquisador, e esta última, tanto ou mais que a primeira, jamais poderá aspirar a uma forma de generalização, pois é limitada por suas próprias peculiaridades.

\section{A CONSTRUÇÃO DO CASO}

Ao contrário de procurar descrever uma realidade psicológica através da história de fatos cronologicamente situados em discurso e conteúdo - como vimos acima - a construção do caso traz à luz uma hipótese metapsicológica. Tal hipótese, que iremos desenvolver a seguir, depende, no entanto, de certa atmosfera caracterizadora do início de uma análise. Muito especialmente naquilo que situa, para o analista, a experiência como algo estranhamente familiar.

Façamos uma digressão necessária. Em seu trabalho intitulado "O estranho" (Das Unheimliche), Freud (1919) ensina “que o estranho provém do familiar que foi recalcado" (p.307). Na situação psicanalítica de tratamento, costuma-se colocar ênfase demasiada e exclusivamente na operação de recalque sofrida pelo paciente e nos complexos infantis que retornam pela via do sintoma. Esse retorno do recalcado é vivido pelo paciente como uma experiência cuja estranheza não deixa de 
revelar, nos tropeços da linguagem, por exemplo, uma evidência de sua familiaridade com esta experiência. Todavia, o que nos interessa aqui, no momento, não é a experiência do paciente com aquilo que lhe parece estranho e familiar ao mesmo tempo. O que devemos ressaltar, aproveitando a sugestão de Fédida (1992), é o que há de enigmático no encontro do analista com cada nova direção de tratamento realizada por ele.

Ainda que haja um inconsciente que se atualiza pela via da transferência, essa genealogia não pode ser tomada como fixa para todos os tratamentos. Para o analista traquejado na experiência clínica é, muitas vezes, tentador deixar-se levar pela onipotência de seu imaginário em relação a determinado tipo de estrutura, de alguma peculiaridade transferencial da histeria ou da fobia, por exemplo, que se repete em diversos casos recebidos. Reside aí o risco de tomar a clínica psicanalítica por uma clínica do imaginário quando, na verdade, a clínica psicanalítica é uma clínica do real. Por isso, evocamos uma vez mais o ensino de Fédida: é preciso, mais do que nunca, aproveitar o caráter especular do psicopatológico do paciente e refleti-lo na psicopatologia da contratransferência. Podemos reproduzir aqui sua interrogação:

“Aquilo que designamos por contratransferência' não seria também a experiência por assim dizer trans-subjetiva - que informa o analista sobre sua própria compulsão à repetição e que lhe designa em negativo o lugar de sua impossível resposta à fala do paciente?" (FÉDIDA, 1992, p.218)

Para que o analista possa descobrir as implicações transubjetivas de sua compulsão a repetir algo, bem como o lugar em negativo de sua impossível resposta à demanda do paciente, é necessário evocar uma alteridade para o trabalho de supervisão. No estudo de caso basta a teoria para informar se a dimensão empírica que a clínica representa está ou não confirmada. Mas para que haja construção do caso é preciso que a situação psicanalítica de supervisão sirva como espaço de interlocução entre o analista e a alteridade supervisora: "a análise de supervisão é instauradora e constitutiva daquilo que se pode chamar de um caso na psicanálise" (FÉDIDA, 1992; p.231). O supervisor cumpre, assim, a função de alteridade na construção do caso. Assim sendo, a hipótese metapsicológica será mais que uma teoria que se formula sobre determinado aspecto da clínica: será uma práxis in statu nascendi, pois que mais é a clínica psicanalítica senão a dimensão de uma práxis que se renova em cada direção de tratamento? Fédida salienta que:

“O começo da análise é — não é difícil imaginar — o enigmático encontro com aquilo que provém de uma vida não se assemelhando em nada a qualquer outra e que no entanto forma a questão genealógica do desvio necessário às transferências e às 
transmissões. O caso de análise seria exatamente o seguinte: não o efeito de ilusão de um déjà-vu, mas o poder deste falso reconhecimento, impotente para se constituir em um ato falho ou em um resto de vida. O analista só começa a saber que o paciente tornar-se-á 'um caso de análise' em razão mesmo do recalque que sua fala provoca nele, no próprio decorrer das sessões.” (FÉDIDA, 1992, p.217).

Se o caso é constituído a partir do relato que recebe status de apresentação pública na situação psicanalítica de supervisão é preciso admitir que há aí uma memória restaurada. Mas o processo de restauração dessa memória não segue, como no estudo de caso, uma ordem cronológica. Na construção do caso o que interessa é uma memória lógica:

“Assim, se o caso é constituído por meio de um relato ou, pelo menos, de uma relação de eventos de sua história pessoal, será então possível falar verdadeiramente de 'casos' em psicanálise, já que a exterioridade pública do desenrolar de um tratamento faz aparecer apenas acontecimentos exemplares cuja expressão literária por maior que seja sua qualidade - muda de fato os tempos da fala e de sua escuta, assim como as transferências implicadas? A estrutura de um relato de caso não seria antinômica com a construção da memória da situação psicanalítica?” (Idem, p.228)

Por fim, o instrumento utilizado pelo pesquisador psicanalítico na construção do caso é a transferência que ocorre nos dois momentos da pesquisa: durante o tratamento analítico e durante a supervisão do caso.

\section{CONSIDERAÇÕES FINAIS}

Traçamos aqui algumas aproximações preliminares acerca de uma tentativa de exposição do método da pesquisa psicanalítica. Cumpre salientar, uma vez mais, que o método da pesquisa psicanalítica depende muito de seu conhecimento na experiência de Freud, primeiro pesquisador psicanalítico, e de sua apropriação pelo autor-pesquisador que o deseja refundar numa situação de pesquisa. Todavia, podemos arriscar observar que uma pesquisa psicanalítica exige de seu autor a posição de principal participante. O que não surge como uma característica exclusiva dela, pois em outras orientações metodológicas o autor também aparece como participante fundamental, mas em pesquisa psicanalítica, essa é uma condição que deve ser sublinhada ao máximo e preconizada como premissa básica da relação entre o mundo subjetivo do autor e o mundo objetivo da realidade investigada. Sem esquecer, no entanto, que quando se trata de uma investigação posta sobre o que chamamos realidade psíquica, as noções de subjetivo e objetivo se relativizam e, por isso mesmo surpreendem pela riqueza de paradoxos e contradições possíveis quando encontramos a lógica subversiva das 
formações do inconsciente. Ademais, o trabalho com o significante, e não com o signo, é outra característica a ser mencionada como fundamental. Finalmente, as inovações em relação à comunicação dos resultados, através da construção do caso e do ensaio metapsicológico surgem como princípios de um novo estilo de pesquisa.

É preciso reconhecer, no entanto, a importância e a necessidade de se estabelecer um contexto de permanente discussão acerca da proposição de um método para a pesquisa psicanalítica. Todavia, tal discussão não retira o mérito das produções que vêm se inscrever sob a égide desta nova orientação cada vez mais presente nos trabalhos de alguns pesquisadores que procuram por uma plataforma metodológica para a pesquisa inaugurada por Freud, a qual ainda se mantém viva graças ao trabalho de seus herdeiros.

Recebido em 10/10/2002. Aprovado em 27/1/2003.

\section{REFERÊNCIAS}

ADORNO, T. (1965) Der Essay als Form. Frankfurt: Suhrkamp.

ALLONNES, C. R. (1989) La démarche clinique en sciences humaines: documents et méthodes. Paris: Bordas.

BOUVERESSE, J. (1987) Le mythe de l'intériorité. Paris: Les Éditions de Minuit.

CAON, J. L. (1994) O pesquisador psicanalítico e a situação psicanalítica de pesquisa. Psicologia: Reflexão e Crítica, 7 (2).

(1996) "Psicanálise <> metapsicologia", in História, clínica e perspectiva nos cem anos da psicanálise. SLAVUTZKY, A., BRITO, C. L. S. \& SOUZA, E. L. A. (orgs.) Porto Alegre: Artes Médicas.

CARNAP, L. (1929) Der Logische Aufbau der Welt. Berlin: Höfmann.

DOR, J. (1993) Introdução à leitura de Lacan, v. 1. Porto Alegre: Artes Médicas. FÉDIDA, P. (1992) Nome, figura e memória: a linguagem na situação psicanalítica.

São Paulo: Escuta.

FERENCZI, S. (1993) Diário clínico. Rio de Janeiro: Imago.

FREUD/FLIESS. (1993). Correspondência completa. Rio de Janeiro: Imago.

FREUD, S. (1976) Edição Standard Brasileira das Obras Psicológicas Completas de Sigmund Freud, Rio de Janeiro, Zahar.

(1910) “Contribuições à psicologia do amor”, v. XI, p.147-157.

(1919) “O estranho”. v. XVII, p.275-314.

(1938) “Breves Escritos”, v. XXIII, p.335-336.

GARCIA-ROZA, L. A. (1996) Introdução à metapsicologia freudiana, v 2. Rio de Janeiro: Zahar.

GUTIERREZ, J. \& DELGADO, J. M. (1995) Técnicas cualitativas de investigación en ciencias sociales. Madrid: Síntesis.

HUSSERL, E. (1990) Méditations Cartésiennes: introduction a la phenomenology. Paris, Librairie Philosophique J. Vrin. 
JAKOBSON, R. (1963) Afasias. São Paulo, Duas Cidades.

JURANVILLE, A. (1986) Lacan e a filosofia. Rio de Janeiro, Jorge Zahar.

KOFMAN, S. (1995) A Infância da Arte. São Paulo: Relume-Dumará.

LACAN, J. M. (1998) Escritos. Rio de Janeiro: Jorge Zahar.

LAPLANCHE, J. (1987) Nouveaux fondements pour la psychanalyse. Paris: Pour.

MALINOWSKI, J. (1937/1976) Os argonautas do Pacífico Ocidental. São Paulo: Abril Cultural.

MAUSS, M. (1947) Manuel d'ethnographie. Paris: Payot.

NASIO, J. D. (1997) O olhar em psicanálise. Rio de Janeiro: Jorge Zahar.

PETRY, L. C. Metalíngua: a questão da metalinguagem e seu sentido na psicanálise. Texto da comunicação realizada como intervenção na conferência de J. L. CAON, Psicopatologia do conceito e psicopatologia do sintoma, na Unisinos, em 5 de novembro de 1993, inédito.

SAUSSURE, F. (1990) Curso de lingüística geral. São Paulo: Edusp.

SCHLICK, M. (1936) Meaning and experience. The Philosophical Review, 45, p. 23-40.

SILVA, M. E. L. (org.) (1993) Investigação e psicanálise. Campinas: Papirus.

SOUZA, A. M. (1998) Transferência e Interpretação - ensaio clínico lacaniano. Porto Alegre: Artes Médicas.

STAKE, R. E. (1994) Handbook of qualitative research. London: Sage.

YIN, R. K. (1993) Applications of case study research. London: Sage.

Isac Nikos Iribarry

Instituto de Psicologia, UFRGS

Laboratório de Psicanálise e Aprendizagem

Rua Ramiro Barcelos, 2600

90035-003 Porto Alegre RS

Telefax (51) 3316-52 46

nikos@plug-in.com.br 